\title{
O Ano das Estruturas 3D de Metaloproteínas - 1995
}

\author{
J O SÉ J . G. MOURA *
}

Durante o ano de 1995 foram publicadas muitas estruturas de metaloproteínas com desempenho chave em processos metabólicos primordiais e esperadas con grande ansiedade pela comunidade científica. Este artigo resulta de uma reflexão sobre a relação estrutura-função em metaloproteínas e lança um convite à consulta da informação contida nos artigos originais, insubstituíveis no detalhe e beleza das estruturas mencionadas.

Metaloenzimas são um grupo muito particular de (bio)catalisadores, onde por um consórcio estrutural muito íntimo entre cadeia polipeptídica e centro(s) metálico(s) (mono, poli, homo ou heteronuclear) se estabecem relações/propriedades particulares e únicas, que não resultam de um mero somatório das propriedades dos elementos constituintes, mas representam um valor acrescentado. Estrutura e função são duas palavras que se relacionam e uma pode conduzir à outra. A resolução de uma estrutura tridimensional permite a definição do arranjo estrutural do catalisador e representa uma etapa necessária para alcançar o objectivo final: a compreensão do mecanismo de acção.

Estes problemas são multifacetados e requerem em geral a contribuição de várias abordagens complementares que cobrem aspectos científicos diversos da biologia, passando pela química e física até à biologia molecular. A determinação da estrutura de uma proteína é um trabalho complexo que encontra em geral resposta em estudos de difracção de raios-X. Em certos casos (massa moleculares menores que $20 \mathrm{kDa}$ e estados magnéticos adequados) pode ser complementada (mesmo substituída) por RMN multidimensional. No entanto, quando possível, a aplicação de ambos os métodos pode permitir retirar conclusões interessantes, em particular sobre a comparação de estruturas no estado sólido e em solução.
Uma das limitações da aplicação destas metodologias é a quantidade de material biológico puro disponivel; outra é a obtenção de cristais adequados (nativos e derivados de átomos pesados). Nos últimos anos assitimos a uma melhoria dos métodos de purificação de proteínas. As técnicas da área da biologia molecular permitiram a clonagem e sobreexpressão de muitas proteínas. As técnicas de cristalização adquiriram maior sistematização e eficácia. O equipamento espectroscópico é mais poderoso e a análise computacional mais potente. Destes factores resulta que o leitor atento à bibliografia especializada se encontra num ponto de viragem. Em 1995, foi possível ter acesso a um elevado número de estruturas cristalográficas de metaloproteínas que representam não só uma etapa de elevada sofisticação do "state of the art", mas, mais ainda, nos presentearam com a definição de centros catalíticos que os livros de texto da bioquímica nos fizeram sonhar durante anos e anos. A estrutura dos centros catalíticos da oxidase do citocromo $c$, a enzima chave do processo respiratório, foram revelados, já não mencionando a análise estrutural dos centros catalíticos dos processos conducentes ao consumo e produção de hidrogénio e a definição de novos centros metálicos contendo molibdénio (ou tungsténio), modelos de enzimas de grande interesse médico, i.e. oxidase da xantina, entre outros.

Como espectroscopista, também gostaria de deixar aqui uma reflexão: muitas destas estruturas foram investigadas, durante anos e anos, por métodos alternativos e complementares: RMN, RPE (ENDOR, ESEEM), EXAFS, DCM, R Raman, Mössbauer, etc. Na maioria dos casos, muitos aspectos estruturais tinham sido revelados e foram agora confirmados. No entanto, noutros, aspectos surpreendentes (caso do novo centro dinuclear heterometálico em hidrogenases) mostraram as limitações da metodologia usada e lançam agora novos desafios.

A riqueza estrutural, a inovação e imaginação das soluções apresenta- das pelos biocatalisadores mais uma vez pode ser um tema a explorar pela química mimética/sintética.

O texto está organizado por tópicos, não pretende ser exaustivo e as referência originais são facilmente encontradas pelos títulos no final, não sendo indicadas expressamente no texto. Referências muito específicas (menos abundantes) são inseridas no texto. A descrição estrutural abreviada pretende dar ênfase aos pontos relevantes e localizar o interesse do caso em discussão. A Tabela I apresenta de um modo sumário as características das metaloproteínas e dos centros activos em consideração.

\section{RESPIRAÇÃO E UTILIZAÇÃO DE OXIGÉNIO - FONTE DE ENERGIA}

A cadeia respiratória permite usar energia libertada por electrões derivados de processos metabólicos na formação de gradientes protónicos e de ATP. A oxidase do citocromo $c$ é a enzima que catalisa a etapa final do processo, i.e., a transferência de electrões ao oxigénio molecular, o qual é convertido a água. Os dados estruturais recentemente disponibilizados permitem discutir a função da enzima no contexto da estrutura. A partir da última etapa, o citocromo $c$ transfere electrões ao centro reaccional que reduz a molécula de oxigénio, num processo acoplado à criação de um gradiente protónico. Embora a estrutura não esteja ainda completamente resolvida, os aspectos bási$\cos$ e a definição dos centros metálicos estão agora disponíveis. Uma proposta estrutural de um outro membro homólogo (bacteriano) desta larga família de oxidases, mas mais simples, foi também descrita.

\section{Os centros metálicos da oxi- dase do citocromo $c$}

Em 1985 foi resolvida a estrutura muito complexa do centro fotossintético inserido em membrana (J.Deisenhofer, R.Huber and H.Michel, Nature, 318, 618-624 (1985)). Neste momento, a estrutura da oxidase do citicromo 
c isolada do coração de boi, constituída por 13 sub-unidades é, sem dúvida, a mais complexa resolvida a nível atómico $(2.8 \AA)$. Dados estruturais tinham sido anticipados por métodos espectroscópicos diversos. A enzima contem 2 hemos ( $\left.\underline{\mathrm{a}} \mathrm{e} \underline{\mathrm{a}}_{3}\right), 3$ átomos de cobre ( 2 $\mathrm{Cu}_{\mathrm{A}}$ e $\left.1 \mathrm{Cu}_{\mathrm{B}}\right), \mathrm{l}$ átomo de magnésio e 1 átomo de zinco. Um centro dinuclear contendo 2 átomos de cobre $\left(\mathrm{Cu}_{\mathrm{A}}\right)$ com uma estrutura semelhante a um centro [2Fe-2S] foi determinada. O par hemo $\underline{a}_{3}-\mathrm{Cu}_{\mathrm{B}}$, que formam o centro reaccional onde ocorre a reacção com oxigénio, estão distanciádos de $4.5 \AA$, não existindo ligandos comuns entre os átomos de ferro hémico e de cobre, embora seja detectado um acoplamento antiferromagnético forte entre estes sítios. O $\mathrm{Cu}_{\mathrm{B}}$ é coordenado por 3 histidinas. Um resíduo tirosina (proposto anteriormente como ligando) apresenta-se alternativamente muito próximo de um dos ligandos histidina e em interacção por ponte de hidrogénio com um dos grupos laterais substituintes do hemo $\underline{a}_{3}$, fornecendo uma conexão interessante entre o hemo $\underline{\mathrm{a}}_{3}$ e o $\mathrm{Cu}_{\mathrm{B}}$ (papel em transferência intramolecular ou controlo confomacional). Os sítios de coordenação, anteriormente predi- tos para o zinco e magnésio, foram confirmados - o último encontra-se situado entre o hemo $\underline{a}_{3}$ e o $\mathrm{Cu}_{\mathrm{A}}$.

A coordenação axial dos hemos, agora confirmada, fora correctamente predicta por espectroscopia e estudos de mutagénese dirigida. O hemo a está coordenado por duas histidinas e o hemo $\underline{a}_{3}$ por uma histidina.

A estrutura da oxidase do citocromo $c$ de Paracoccus denitrificans (numa forma complexada a um anticorpo) foi também descrita. Embora mais simples (4 sub-unidades) existe uma forte homologia entre os centros reaccionais descritos e os da enzima bovina.

Têm sido avançadas algumas propostas sobre o acoplamento da transferência electrónica e a translocação protónica.

\section{PEROXIDASE DI-HÉMICA}

Oxigénio na forma de peróxido pode ser tóxico. A peroxidase é uma enzima envolvida em protecção, disponibilizando dois equivalentes redutores ao substrato. A peroxidase do citocromo $c$ isolada de Pseudomo- nas aeroginosa (utilizando dois centros hémicos) representa uma nova classe de peroxidases que não passam pela formação de intermediários catalíticos radicalares, como no caso de peroxidases monohémicas. A enzima é constituída por uma cadeia polipeptídica única (323 aminoácidos) contendo dois hemos do tipo $c$ (ligados de modo covalente). A estrutura foi resolvida a $2.4 \AA$, na forma oxidada. Um dos hemos apresenta uma coordenação axial com duas histidinas, His55 e His 71 (-330 $\mathrm{mV}$ ) e o outro é coordenado por His20 e Met275 (+320 mV). A estrutura sugere que a formação da forma activa da enzima (forma semi-reduzida) envolve alteração de conformação de pelo menos um dos hemos, atingindo-se uma forma hémica de spin-alto, em que a His71 não está coordenada. Gera-se assim estruturalmente um centro peroxidático, com uma posição de coordenação disponível para interacção com a molécula de substrato. Uma sequência de eventos semelhante é sugerida para a peroxidase dihémica, isolada de Paraccocus denitrifians (I.Moura e G.Pettigrew, comunicação pessoal).

TABELA I

\begin{tabular}{|c|c|c|}
\hline Metaloproteína & Resolução $(\AA)$ & Aspectos Estruturais - Centros metálicos - Coordenação \\
\hline oxidase do citocromo $c$ (coração de boi) & 2.8 & $2 \mathrm{Cu}_{\mathrm{A}}$, heme $\underline{\mathrm{a}}(\mathrm{His}, \mathrm{His})$, heme $\underline{\mathrm{a}}_{3}(\mathrm{His})-\mathrm{Cu}_{\mathrm{B}}, \mathrm{Zn}^{2+}, \mathrm{Mg}^{2+}$ \\
\hline P. denitrificans oxidase do citochromo $\mathrm{C}$ & 3.8 & idem \\
\hline$P$. aeruginosa peroxidase do citocromo $C$ & 2.4 & heme $_{A} c\left(\right.$ His55, His71), heme ${ }_{B} c($ His20, Met275) \\
\hline T. pantotropha redutase de nitrito $\left(c d_{1}\right)$ & 1.55 & heme $c$ (His17,His65), heme $d_{1}($ Tir25,His200) \\
\hline K. aerogenes urease & 2.2 & $\begin{array}{l}\mathrm{Ni}(\mathrm{A})-\mu\left[\text { Lis } 217 \text { (modificada) } \mathrm{COO}^{-}\right]-\mathrm{Ni}(\mathrm{B}) \\
\mathrm{Ni}(\mathrm{A})\left(\mathrm{His} 34, \mathrm{His} 36, \mathrm{Asp} 360, \mathrm{H}_{2} \mathrm{O}\right) \\
\mathrm{Ni}(\mathrm{B})(\mathrm{His} 246, \mathrm{His} 272)\end{array}$ \\
\hline E.coli redutase de sulfito & 1.6 & Siroheme $-\mu$ (S-Cis)-[4Fe-4S], [4Fe-4S] \\
\hline $\begin{array}{l}\text { D.gigas hidrogenase } \\
2 \times[4 \mathrm{Fe}-4 \mathrm{~S}],[3 \mathrm{Fe}-4 \mathrm{~S}]\end{array}$ & 2.8 & 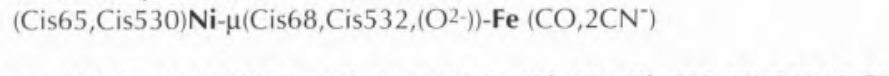 \\
\hline $\begin{array}{r}\text { E.coli redutase de ribonucleotídeo férrico } \\
\text { ferroso }\end{array}$ & $\begin{array}{l}(*) \\
1.7\end{array}$ & $\begin{array}{l}\text { (His1 18,Asp84,H2O)Fe- } \mu \text { (Glu115,(O))-Fe (Glu204, Glu238, His241, }{ }_{2} \mathrm{O} \text { ) } \\
\text { (His118,Asp84)Fe- } \mu \text { (Glu115,Glu238)-Fe (Glu204, His241) }\end{array}$ \\
\hline D.gigas oxido-redutase de aldeído & 2.2 & {$\left[\operatorname{Pterin}(\mathrm{S})_{2}\right]-\mathrm{Mo}-\left[=\mathrm{O}=\mathrm{O}\right.$ ou S), $\left.\mathrm{H}_{2} \mathrm{O}\right]$} \\
\hline P.furiosus oxido-redutase de aldeído & 2.3 & $2 \times\left[\right.$ Pterin $\left.(\mathrm{S})_{2}\right]-\mathrm{W}-[=\mathrm{O},=\mathrm{O}$ ?] \\
\hline$R$. sphaeroids redutase do DMSO & 2.2 & $\left.2 \times\left[\operatorname{Pterin}(\mathrm{S})_{2}\right]-\mathrm{Mo}-\mathrm{I}=\mathrm{O}, \mathrm{Ser} 147\right]$ \\
\hline $\begin{array}{l}\text { E.coli desidrogenase do formato } \\
\text { fosfatase ácida púrpura (planta) }\end{array}$ & 2.6 & $\begin{array}{l}2 \times\left[\text { Pterin }(\mathrm{S})_{2}\right]-\mathrm{W}-[=\mathrm{O}, \text { Se-Cis }] \\
2.9 \text { (A)Fe - } \mu \text { (Asp64-monodentado, } \mathrm{OH}-)-\mathbf{Z n}(\mathrm{B}) \\
\text { A - (Tir167, Asp 135, His325, } \mathrm{OH}-?) \\
\text { B - (His323, His286, Asn201, } \mathrm{H}_{2} \mathrm{O} \text { ?) } \\
\mathrm{Fe} \text { (Cis) }\end{array}$ \\
\hline D. gigas desulforedoxina & 1.8 & $\mathrm{re}(\mathrm{CIS})_{4}$ \\
\hline
\end{tabular}




\section{CICLOS DE ELEMENTOS QUímICOS}

\section{Enxofre e Azoto - redução de sulfito e nitrito}

Redutases de sulfito e de nitrito são enzimas chave de processos biossintéticos assimilativos envolvendo compostos de enxofre e de azoto e dissimilativos utilizando iões oxidados destes elementos em mecanismos de transdução energética. Redutases assimilativas de sulfito e de nitrito, isoladas em bactérias, fungos, algas e plantas fornecem enxofre (estado-2) e azoto (estado -3) reduzidos necessários para a incorporação em biomoléculas (por exemplo enxofre e azoto na síntese de amino ácidos).

A redução assimilativa de nitrato a amónia passa pela redução de dois electrões de nitrato a nitrito e subsequente redução directa por 6 electrões a amónia. Em contraste, o processso de desnitrificação transforma nitrato a nitrito, óxido nítrico, óxido nitroso e finalmente azoto em processos de redução sequenciais envolvendo um ou dois electrões. A redução assimilitava transforma mais nitrato em amónia que o processo de fixação de azoto via nitrogenase. A via dissimilativa pode ainda dar origem a amónia a partir de nitrito (enzimas multihémicos).

A redução de nitrito é levada a cabo por um sistema diversificado de enzimas em termos de centros catalíticos e produtos da reacção:

- enzimas contendo cobre (estrutura resolvida a $2.3 \AA$, J.W.Godden, S.Turley, D.C.Teller, E.T. Adman, M.Y.Liu, W.J.Payne and J.LeGall, Science, 253, 438-442 (1991)) que reduzem nitrito a NO

- enzimas contendo hemos tipo $c$ e $d_{1}$ (descritas a seguir) que reduzem nitrito a $\mathrm{NO}$

- enzimas contendo sirohemo e centros ferro-enxofre (análogos às enzimas que reduzem sulfito a sulfureto, descritas a seguir) que reduzem nitrito a amónia.

Durante a redução dissimilativa de sulfito (em particular em bactérias redutoras de sulfato) o sulfito (via sulfato) pode actuar como aceitador de electrões durante a respiração anaeróbica. O produto final é sulfureto. Excesso de sulfureto acumulado por esta via, pode ter implicações no geociclo do enxofre, em efeitos nocivos para o ambiente e em problemas relacionados com corrosão de metais ferrosos.

Citocromo $c d_{1}$, uma enzima bifuncional: redução de nitrito a óxido nítrico e redução de oxigénio a água

A respiração de oxigénio é um processo obrigatório e fundamental para a maioria dos eucariontes. Procariontes usam frequentemente outros aceitadores electrónicos (sulfato, nitrato, dióxido de carbono, protões, etc.). Tem sido proposta uma relação evolutiva entre enzimas que reduzem oxigénio e enzimas envolvidos na desnitrificação (nitrito em vez de oxigénio). o citocromo $c d_{1}$ é uma enzima bifuncional que cataliza a redução mono-electrónica de nitrito a óxido nítrico $\left(\mathrm{NO}_{2}{ }^{-}+2 \mathrm{H}^{+}+1 \mathrm{e}\right.$ $\leftrightarrow \mathrm{NO}+\mathrm{H}_{2} \mathrm{O}$ ) e a redução de 4 electrões de oxigénio a água $\left(\mathrm{O}_{2}+4 \mathrm{H}^{+}\right.$ $+4 \mathrm{e} \leftrightarrow 2 \mathrm{H}_{2} \mathrm{O}$ ). A estrutura da redutase de nitrito de Thiosphaera pantotropha foi obtida com uma resolução de $1.55 \AA$. Cada subunidade do homodímero contem 1 hemo do tipo $c$ ligado de modo covalente à cadeia polipeptídica com dois resíduos Histidina (His 17, His 69) em posição axial e um hemo $d_{1}$ (estrutura que apresenta saturação parcial da porfirina e grupos carboxilatos substituintes no anel) não covalentemente ligado com coordenação axial Tirosina e Histidina (Tir25, His200). O hemo $d_{1}$ é o centro reaccional onde ocorre a redução de nitrito e de oxigénio. Os dois hemos estão localizados em domínios diferentes e a activação da enzima requer que o hemo $d_{1}$ esteja penta-coordenado (spinalto) para que exista uma posição de coordenação vaga que permita a interacção com a molécula de substrato. A tirosina é o ligando que deve não coordenar no estado reduzido da enzima (V.Fülöp, comunicação pessoal).

\section{Sulfito redutase - redução de aniões inorgânicos}

A estrutura da redutase de sulfito de Escherichia coli, responsável pela redução de sulfito a sulfureto (etapa de 6 electrões), análoga da redução de nitrito a amónia, indica a presença de um centro hémico particular (sirohemo) e múltiplos cofactores cubanos do tipo [4Fe-4S]. Um novo centro reaccional foi encontrado associando o sirohemo a um agregado [4Fe-4S], através de um ligando comum - o grupo tiol de um resíduo cisteína. O ferro hémico coordena fosfato na forma nativa. O complexo formado com sulfito, indica que o substrato se liga via o átomo de enxofre ao sirohemo substituindo a molécula de fosfato. Os grupos carboxilato na periferia do grupo sirohemo são sugeridos estarem envolvidos na activação da ligação S-O (clivagem por redução).

\section{AZOTO - PROCESSAMENTO DE UREIA}

A urease é uma enzima que cataliza a hidrólise de ureia um importante produto final do metabolismo com formação de amónia e carbamato. Ureases dependentes de níquel podem ser isolada em bactérias, fungos e plantas e têm um papel fundamental, permitindo aos organismos usarem ureia, gerada interna e externamente, como fonte de azoto. Do ponto de vista agrícola, as ureases bacterianas podem indisponibilizar ureia usada como fertilizante, na forma de azoto volátil. A urease foi a primeira enzima a ser cristalizada e decorreram 70 anos até que os segredos moleculares do processo catalítico e estrutura do centro activo fossem revelados.

\section{A estrutura da urease}

A urease isolada de Klebsiella aerogenes é constituída por três subunidades $(\alpha-60.3, \beta-11.7$ e $\gamma$-11.1 kDa) formando um complexo $\left(\alpha b_{2} \gamma_{2}\right)_{2}$ e a estrutura foi determinada com uma resolução de $2.2 \AA$. O centro catalítico contem dois átomos de níquel a $3.5 \AA$ 
de distância. Um dos átomos de níquel está coordenado por 5 ligandos, His134, His36, Asp360, $\mathrm{H}_{2} \mathrm{O}$, Lis217 e o segundo por 3 ligandos, His 246 . His272 e Lis217. Interessante é a observação de que a Lis217 se apresenta modificada (por reacção com $\mathrm{CO}_{2}, \mathrm{o}$ grupo $\varepsilon$-amino é convertido num grupo carbamato, - $\mathrm{NCOO}^{-}$) e fornece um átomo de oxigénio a cada átomo de níquel, explicando a razão da acção de $\mathrm{CO}_{2}$ na activação da apoenzima. A estrutura é compatível com um mecanismo de acção em que um dos átomos de níquel coordena um dos átomos de azoto de molécula de ureia (completando uma coordenação tetraédrica) e uma molécula de hidróxido (ligando do centro de níquel) reage com o grupo carbonilo.

\section{PRODUÇÃO E CONSUMO DE HIDROGÉNIO, O COMBUSTÍVEL DO FUTURO}

As hidrogenases catalisam uma reacção de oxidação-redução fundamental e a mais simples: a activação da molécula de hidrogénio, $\mathrm{H}_{2} \leftrightarrow$ $2 \mathrm{H}^{+}+2 \mathrm{e}^{-}$. As hidrogenases desempenham um papel chave no metabolismo anaeróbico bacteriano e um elo importante em bioenergética e na produção de biofuel (hidrogénio e metano). Existem duas classes de enzimas: hidrogenases $\mathrm{Fe}$, contendo exclusivamente centros $\mathrm{Fe}-\mathrm{S}$ e hidrogenases [NiFe] com um centro reaccional contendo níquel e centros [Fe-S] (sub-grupo, as hidrogenases [NiSeFe] contêm selenocisteína).

\footnotetext{
A estrutura da hidrogenase [NiFe]

Um estudo cristalográfico recente (resolução $2.8 \AA$ ) da forma nativa da hidrogenase isolada da bactéria redutora de sulfato Desulfovibrio (D.) gigas mostrou que o centro activo é constituído por um novo centro heterodinuclear contendo níquel e um outro metal de transição (ferro). Este resultado, inesperado, lança um desafio aos estudos espectroscópicos anteriormente publicados que falharam na definição precisa deste centro.
}

A hidrogenase [NiFe] é composta por duas subunidades: $26 \mathrm{kDa}$ e 63 kDa. A subunidade menor contém dois centros [4Fe-4S] e um centro [3Fe-4S]; o centro catalítico (onde ocorre a interacção com a molécula de hidrogénio e protões) contem níquel e está localizado na subunidade maior. É bem reconhecido um percurso que favorece a interacção entre os centros, que se estende desde o centro [4Fe-4S] dito "distal" e situado na periferia da molécula (com um átomo coordenante histidina, que substitui uma cisteína, o ligando usual) através do centro [3Fe-4S] (intercalado entre os centros tetranucleares) até ao centro [4Fe-4S] próximo do centro reaccional com níquel. Com grande surpresa, a estrutura tridimensional revelou que o centro catalítico era heterodinuclear (Figura 1). O átomo de níquel é coordenado por quatro cisteínas, Cis65, Cis68. Cis530 (substituída por selenocisteína em hidrogenases [NiSeFe]) e Cis533; Cis68 e Cis533 são ligandos em ponte entre o átomo de níquel e um metal não identificado. Este segundo metal está coordenado por três ligandos não proteícos (moléculas diatómicas) propostas recentemente por medidas independentes por FTIR serem monóxido de carbono e cianeto (R.P.Happe, W.Roseboom, K.A.Bagley, A.J.Pierik and S.P.J.Albracht, Nature, 385, 126 (1997). Um outro ligando não proteico, provavelmente envolvendo oxigénio, também colocado em ponte entre o níquel e o ferro, completa as esferas de coordenação dos iões metá-

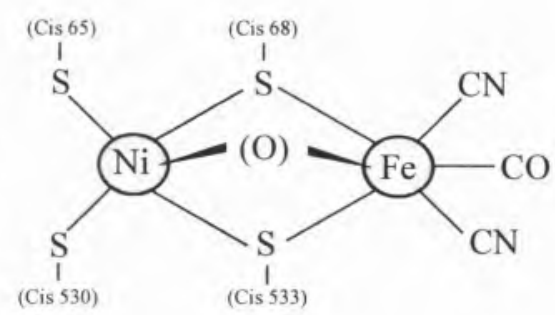

Fig. 1 - O novo centro activo heterodinuclear da hidrogenase [NiFe] licos. A análise de efeitos de dispersão anómala (M.Frey, comunicação pessoal), EXAFS (Z.Gu, J.Dong, C.B.Allan, S.B.Choudhury, R.Franco, J.J.G.Moura, I.Moura, J.LeGall, A.E.Przybyla, W.Roseboom, S.P.J.Albracht, M.J.Axley, R.A.Scott and M.J.Maroney, J.Am.Chem.Soc., 118 , 11155-11165 (1996)) e estudos de ${ }^{57} \mathrm{Fe}$ ENDOR nos sinais de RPE do níquel (J.Huyett, M.Carepo, A.Pamplona, R.Franco, I.Moura, J.J.G. Moura and B.Hoffman (1996) submetido para publicação) completam a identificação do segundo metal como ferro.

\section{A ORIGEM DA VIDA}

Redutase de ribonucleotídeo

As redutases de ribonucleotídeo catalisam a formação de deoxiribonucleotídeos essenciais na síntese de ADN. Estas enzimas correlacionam AND e ARN, uma etapa fundamental no processo de evolução e transmissão de informação. A subunidade, designada por R2, isolada de Escherichia coli, é um homodímero contendo um centro binuclear de ferro por monómero. Um radical tirosina é essencial para a catálise. A espécie radicalar é formada após reacção do estado ferroso com dioxigénio. A estrutura do estado ferroso foi resolvida a $1.7 \AA$ (existe também a estrutura de um mutante a $2.2 \AA$ ). A estrutura do estado diférrico foi determinada anteriormente. Em ambas as formas, a coordenação do centro dinuclear é dominada por carboxilatos de cadeias laterais de aminoácidos (Figura 2). No estado reduzido é notória a alteração conformacional em três dos carboxilatos e de um ligando em ponte ( $\mu$-oxo) e duas moléculas de água saem da esfera de coordenação do centro metálico. A coordenação dos átomos de ferro muda de seis para quatro após redução, explicando a alta afinidade do sítio catalítico para oxigénio. neste estado de oxidação. Um mecanismo de activação do dioxigénio foi proposto baseado nos dados estruturais estabelecidos na forma oxidada e na forma reduzida. 
(A)

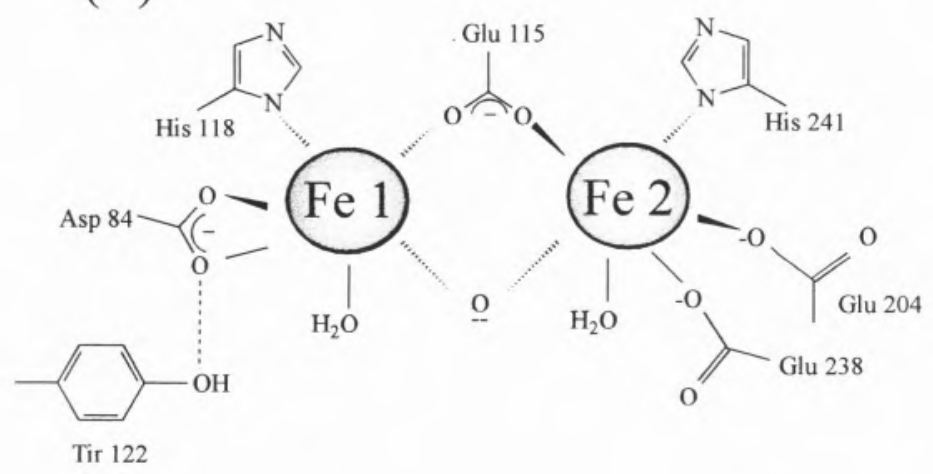

(B)
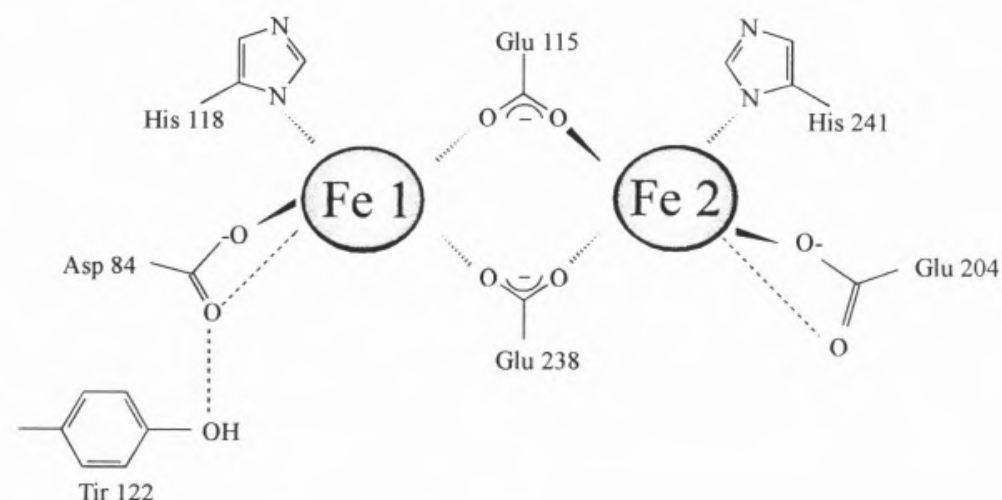

Fig. 2 - O centro catalítico da redutase de ribonucleotídeo

(A) forma diférrica

(B) forma diferrosa

\section{MOLIBDÉNIO E TUNGSTÉNIO EM BIOLOGIA}

Enzimas contendo molibdénio desempenham papéis importantes em variadas reacções biológicas (metabolismo de carbono, azoto e enxofre). A fixação de azoto é realizada por enzimas especializadas contendo molibdénio inserido em agregados heterometálicos com molibdénio, ferro e enxofre. Esta estrutura, resolvida em 1992, teve grande impacto, redefinindo o agregado catalítico (J.Kim and D.C.Rees, Science, 257, 1677-1682 (1992)). Todas as outras enzimas contendo molibdénio associam este metal a um cofactor orgânico (pterina) e incluem enzimas importantes tais como hidroxilases de molibdénio, i.e., oxidase de xantina e oxido-redutases de aldeído (conversão de aldeídos aos correspondentes ácidos carboxílicos), redutase de nitrato, oxidase de sulfito e redutases respiratórias - redutase do dimetilsulfóxido (DMSO).

A participação de tungsténio em biologia tem sido menos explorada. Contudo, desde há alguns anos que este metal é considerado como constituinte de desidrogenases de formato (oxidação-redução do par formato $\left./ \mathrm{CO}_{2}\right)$. Uma oxido-redutase de aldeído contendo tungsténio foi isolada de organismos hipertermofílicos.

\section{oxido-redutase de aldeído} (Mo)

A estrutura cristalina da oxidoredutase de aldeído isolada da bacté- ria redutora de sulfato, Desulfovibrio gigas foi determinada a uma resolução de $2.25 \AA$ A. A proteína é um homodímero de subunidades com 907 amino ácidos cada, e pertence à família da oxidase de xantina. Contém um cofactor molibdopterina (Moco) e dois centros [2Fe-2S] distintos. A proteína está organizada em quatro domínios, dos quais os dois primeiros coordenam os centros de ferroenxofre e os últimos dois estão envolvidos na ligação do cofactor. Moco é uma molibdopterina com molibdénio e na forma de dinucleótido da citosina (MCD-molybdopterin citosine dinucleotide). A molibdopterina forma um sistema tricíclico, no qual o biciclo da pterina se encontra fundido com um sistema pirano (Figura 3). O dinucleótido da molibdopterina encontra-se inserido no interior da proteína. O grupo cis-ditioleno do anel pirano coordena o átomo de molibdénio, o qual se liga a três ligandos (oxigénios) adicionais. O Moco não tem ligandos proteícos directamente coordenados.

A estrutura cristalina da oxido-reductase do aldeído foi analisada nas formas modificadas quimicamente. Uma molécula de isopropanol, que está presente no compartimento interior do túnel de ligação do substrato, constitui um modelo para o complexo de Michaelis da reacção com aldeídos. Foi proposto que a reacção ocorra por transferência de uma molécula de água ligada ao molibdénio, como $\mathrm{OH}^{-}$, envolvendo um aminoácido da vizinhança (Glu 869).

\section{(S)}

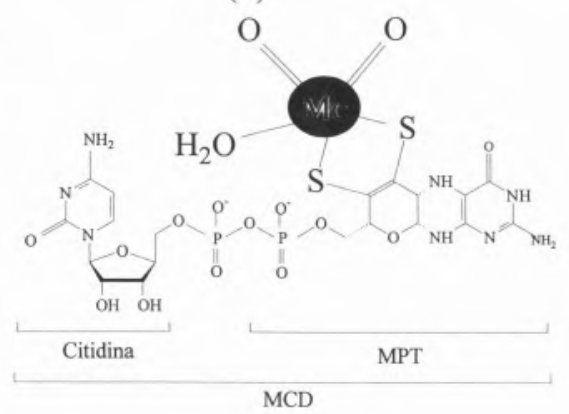

Fig. 3 - O centro catalítico da oxido-redutase de aldeído de $D$.gigas 

(W)

\section{Oxido-redutase de aldeído}

A estrutura da primeira proteína contendo tungsténio foi obtida para a oxido-redutase de aldeído isolada de um organismo hipertermófilo, Pyroccocus furiosus, com uma resolução de $2.3 \AA$ A A proteína é constituída por duas subunidades idênticas, cada uma contendo um centro [4Fe4S] e um átomo de tungsténio ligado, de um modo não esperado, por duas molibdopterinas, MPT-molybdopterin - sem bases adicionais, terminando num grupo fosfato, coordenando assim quatro átomos de enxofre (tiolenos). A molibdopterina forma também um sistema tricíclico, conforme descrito anteriormente. Um ião magnésio parece ter um papel importante em interacção electrostática com os grupos fosfato da molibdopterina.

\section{Redutase de DMSO (Mo)}

A estrutura da redutase de DMSO isolada de Rhodobacter sphaeroides foi resolvida a $2.2 \AA$. A enzima é uma molibdoproteína com diferenças importantes em relação à oxidoredutase de aldeído isolada de D.gigas. O centro contendo molibdénio contem uma espécie mono-oxo e no plano equatorial coordenam quatro átomos de enxofre (tiolenos) originados em duas molidbopterinas na forma de dinucleótido da guanina (MGD-molybdopterin guanine dinu(leotide). As pterinas apresentam diferentes modo de coordenação ao molibdénio, quando se comparam os estados oxidados e reduzido da enzima, sendo sugerido um mecanismo de ligação de substrato que envolve alteração na coordenação de um dos grupos tioleno. Um ligando protéico (Ser147) coordena ao metal em ambos os estados redox analisados.

\section{(W)}

\section{Desidrogenase de Formato}

A desidrogenase de formato isolada de E.coli é uma componente de $80 \mathrm{kDa}$ de um complexo proteíco. Os cristais difractam até $2.6 \AA \AA$ na forma isolada anaerobicamente. A forma reagida com formato também crista- liza. Os dados obtidos indicam uma analogia com a proteína de tungsténio isolada de P.furiosus to Tungsténio está coordenado a duas moléculas idênticas de molibdopterina (MPT)), mas o centro activo interactua com um ligando proteico (selenscisteina).

\section{NOVAS ESTRUTURAS}

Fosfatase Ácida Púrpura centro di-nuclear $\mathrm{Fe}$ (III) - Zn (II)

A fosfatase ácida púrpura isolada de plantas, recentemente caracterizada, contêm um centro dinuclear com $\mathrm{Fe}(\mathrm{III})$ - Zn(II), com semelhanças com as enzimas isoladas de mamíferos com centros $\mathrm{Fe}$ (III)- $\mathrm{Fe}$ (II). A estrutura do homodímero (111 kDa) foi determinada com uma resolução de $2.9 \AA$ Å. A enzima é constituída por dois domínios em cada subunidade. O centro catalítico, localizado na parte C-terminal, apresenta os dois metais à distância de $3.1 \AA$, com um ligando Aspl64 em ponte e actuando como monodentado. As esferas de coordenação dos metais são adicionalmente preenchidas por: ferro [Tir167, His325 and Asp135] e zinco [His286, His323 e Asp201]. Esta estrutura proposta é compatível com as propostas mecanísticas anteriormente discutidas considerando que o mecanismo de hidrólise de ésteres de fosfato envolve o ataque nucleofílico ao grupo fosfato pelo hidróxido coordenado ao átomo de ferro. Três ligandos exógenos - solvente, na esfera de coordenação dos metais estão em discussão.

\section{Desulforedoxina - um novo centro monoférrico não hémico}

Rubredoxinas são as proteínas contendo ferro não hémico mais simples. Apresentam coordenação tetraédrica do átomo de ferro por 4 cisteínas. A estrutura da desulforedoxina de Desulfovibrio gigas, um homodímero (2×36 aminoácidos) representa uma variante da estrutura tipo rubredoxina, em que duas das cisteínas coordenantes são adjacentes na cadeia polipeptídica, impondo uma diferente distorção no centro metáli- co. A estrutura foi obtida com uma resolução de $1.8 \AA$. A estrutura simétrica do dímero coloca os dois átomos de ferro em polos opostos da molécula a uma distância de $16 \AA$. O centro metálico pode ser substituído por diversos metais, processo vantajoso para análise estrutural, nomeadamente síntese de derivados pesados e análise estrutural por RMN (J.J.G.Moura, B.J.Goodfellow, M.J. Romão, F.Rusnak and I.Moura, Comments in Inorg. Chem. (1996) in press).

\section{CONCLUSÕES}

As estruturas de metaloproteínas publicadas no período de tempo analisado fornecem uma grande variedade de soluções estruturais e permitiram a visualização de centros catalíticos de enzimas chave em processos metabólicos. Como se depreende facilmente, o revelar da estrutura 3D não é o fim mas quase que o começo de uma longa história. Os ligandos, as geometrias, as distorçōes apontadas, as vizinhanças, a exposição do centro catalítico vão ser determinantes no modo de acção e condicionar e delinear os mecanismos.

A proposta mecanística para enzimas da família da oxidase da xantina, baseada nos dados estruturais é um exemplo flagrante do poder deste tipo de análise.

Também se compreende que a análise destes casos será enriquecida no futuro pelo estudo complementar de diferentes estados de oxidação e situações de interacção com substratos (inibidores, produtos, análogos...). Na realidade, muitos dos trabalhos analisam formas nativas e não representam as formas activas. É portanto necessário passar das formas "unready" para as "ready".

Uma leitura destes dados leva imediatamente a retirar uma lição importante: alterações conformacionais são determinantes na preparação dos centros metálicos para a reacção de catálise, permitindo que a esfera de coordenação do metal aceite substratos a serem posteriormente processa- 
dos. É bem notório esta ocorrência na peroxidase (criação do centro peroxidático por saída do ligando axial histidina), na redutase de nitrito $\left(c d_{1}\right)$ (com a transformação do hemo $d_{1}$ numa forma de spin-alto por alteração conformacional que conduz à não coordenação da tirosina), na redutase de ribonucleotídeo (com diminuição do número de coordenação dos átomos de ferro após redução) e na redutase de sulfito em que o grupo sulfito compete com o grupo fosfato ligado na posição axial do sirohemo.

Estes exemplos, em particular o caso da redutase de ribonucleotídeo, demonstram que alterações na esfera de coordenação de centros metálicos acoplados a transições redox induzem variação de número de coordenação. A diminuição de número de coordenação permite reactividade do local de reacção com o substrato. O caso dos "carboxylate shifts" observados na redutase de ribonucleotídeo é um dos exemplos de flexibilidade da esfera de coordenação e modulação das propriedades do centro catalítico com base em química de oxidação-redução.

Outro aspecto importante: as estruturas apresentados mostram que, nos casos em que estão presentes centros redox múltiplos e, quando existe necessidade de definir sítios de reconhecimento de substrato e sítios aceitadores electrónicos, um arranjo espacial adequado é conseguido pela colocação estratégica dos centros activos, permitindo a existência de possíveis percursos para a transferência electrónica (Figura 4). Uma consulta detalhada da bibliografia indicada é sugerida. Notórios são os seguintes casos:

\section{hidrogenase}

$e \rightarrow[4 \mathrm{Fe}-4 \mathrm{~S}]$ "distal" $\rightarrow[3 \mathrm{Fe}-4 \mathrm{~S}] \rightarrow$

[4Fe-4S] "proximal" $\rightarrow[\mathrm{Ni}-\mathrm{Fe}] \rightarrow \mathrm{H}_{2}$

oxido-redutase de aldeido

aldeídos $\rightarrow[$ Moco $] \rightarrow[2 \mathrm{Fe}-2 \mathrm{~S}]_{\mathrm{II}} \rightarrow$

$[2 \mathrm{Fe}-2 \mathrm{~S}]_{\mathrm{I}} \rightarrow e$

oxidase do citocromo $\mathrm{C}$

$e \rightarrow \mathrm{Cu}_{\mathrm{A}} \rightarrow$ heme $\underline{\mathrm{a}} \rightarrow$ heme $\underline{\mathrm{a}}_{3}-\mathrm{Cu}_{\mathrm{B}}$ $\rightarrow \mathrm{O}_{2}$
Nestes casos os centros [2Fe$2 \mathrm{~S}]_{\mathrm{I}}$ e $[4 \mathrm{Fe}-4 \mathrm{~S}]$ "distal" estão bastante expostos ao solvente (sítio aceitador de electrões) e os centros catalíti-
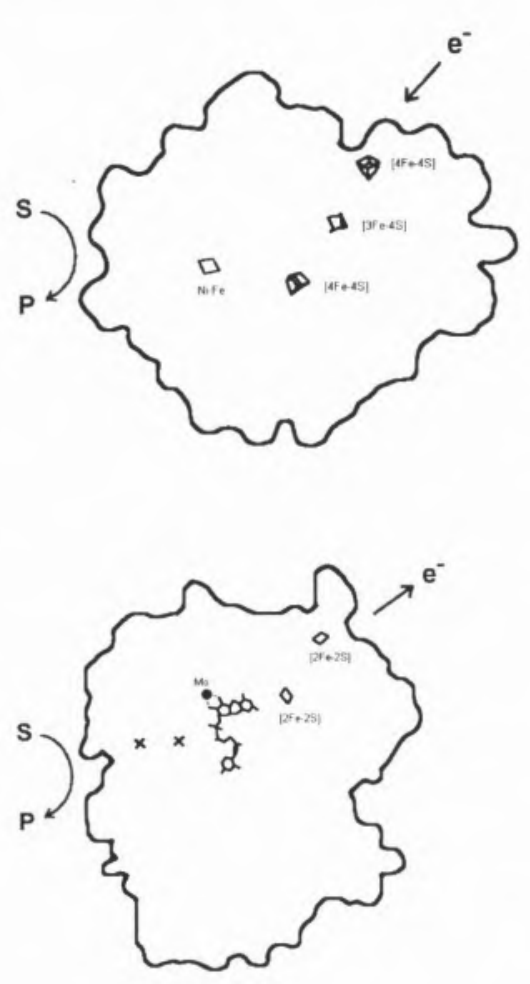

Fig. 4 - Localização espacial de centros redox múltiplos.

(A) hidrogenase

(B) oxido-redutase de aldeído

$\cos$ ([Ni-Fe] e Moco) podem comunicar com o exterior (acessíveis a interacção com o substrato) através de canais bem definidos.

A hidrogenase representa uma situação a explorar em conjunto pela espectroscopia e cristalografia. A coordenação do níquel e ferro são extremamente inovadoras e desafiantes. A análise de amostas em estados redox bem definidos e em interacção com hidrogénio é de grande urgência. O átomo de oxigénio em ponte pode ser o interruptor para o equilíbrio unready/ready e a visualização de catálise do dihidrogénio por coordenação em ponte no centro bimetálico é uma proposta tentadora a demonstrar.

\section{AGRADECIMENTOS}

Estes tópicos são apoiados por projectos financiados pela JNICT e PRAXIS. Agradeço a L.Kriphal, P.N.Palma e R.Duarte o apoio gráfico. Aos membros dos Grupos de Bio-inorgânica (BIOIN) e Bioquímica Física de Proteínas (BFP) do CQFBUNL manifesto o meu agradecimento pelas múltiplas contribuições e discussões científicas. À M.J.Romão (IST) aqui fica também expresso o meu apreço pela colaboração desenvolvida e pela sua constituição no desenvolvimento da cristalografia de proteínas em Portugal. As coordenadas da hidrogenase e oxido-redutase de aldeído de D.gigas foram gentilmente cedidas por M.Frey (Grenoble) e M.J.Romão, respectivamente.

\footnotetext{
* Departamento de Química, Centro de Química Fina e Biotecnologia

Faculdade de Ciências e Tecnologia, Universidade Nova de Lisboa

2825 Monte de Caparica, Portugal

Tel. 351-1-2948382, Fax 3511-1-2948550,

email jose.moura@dq.fct.unl.pt
}

\section{NOTA}

O grupo de R. Huber determinou recentemente a estrutura da redutase de DMSO isolada de R. Capsulatus que apresenta um dos grupos tioleno năo coordenado ao metal (Schneider et. al., J.Mol.Biol., 263, 53-69 (1996)).

\section{REFERÊNCIAS}

Structures of Metal Sites of Oxidized Bovine Heart Cytochrome c Oxidase at $2.8 \AA$

T. Tsukihara, H. Aoyama, E. Yamashita, T. Tomizaki, H. Yamaguchi, K. Shinzawa-ltoh, R. Nakashima, R. Yaono and S. Yoshikawa

Science, 269, 1069-1074 (1995)

Structure at $2.8 \AA$ Resolution of Cytochrome c Oxidase from Paracoccus denitrificans

S. Iwata, C. Ostermeier, B. Ludwig and H. Michel

Nature, 376, 660-669 (1995)

Structure of Cytochrome c Oxidase, Energy Generator of Aerobic Life

R. Gennis and S. Ferguson-Miller

Science, 269, 1063-1064 (1995)

Purpose of Proton Pathways

R.J. P. Williams

Nature, 376, 643 (1995) 
Crystal Structure of The Di-Haem Cytochrome c Peroxidase from Pseudomonas aeruginosa

V. Fülöp, C. I Ridout, C. Greenwood and J. Hajdu

Structure, 3, 1225-1233 (1995)

The Anatomy of a Bifuncional Enzyme: Structural Basis for Reduction of Oxygen to Water and Synthesis of Nitric Oxide by Cytochrome $c d$

V. Fölöp, J. W. B. Moir, S. J. Ferguson and Janos Hajdu Cell, 81, 369-3і7 (1995)

Crystallization and Preliminary Crystallographic Study of Cytochrome $c d_{1}$ Nitrite Reductase from Thiosphaera pantotropha

V. Fölöp, J. W. B. Moir, S.J. Ferguson and J. Hajdu

J. Mol. Biol., 232, 1211-1212 (1995)

The Crystal Structure of Urease from Klebsiella aerogenes E. Jabri, M.B. Carr, R.P. Hausinger, and P. A. Karplus

Science, 268, 998-1004 (1995)

At Last-The Crystal Structure of Urease

S. J. Lippard

Science, 268, 996-997 (1995)

Sulfite Reductase Structure at 1.6 Á: Evolution and Catalysis for Reduction of Inorganic Anions

B. R. Crane, L. M. Siegel and E. D. Getzofi

Science, 270, 59-49 (1995)
Crystal Structure of the Nickel-Iron Hydrogenase from Desulfovibrio gigas

A. Volbeda, M.- H. Charon, C. Piras, E. C. Hatchikian, M. Frey and J.C. Fontecilla-Camps

Nature 373, 580-587(1995)

Splitting Molecular Hydrogen

R. Cammack

Nature, 373, 556-557 (1995)

Crystal Structure of Reduced Protein R2 of Ribonucleotide Reductase: The Structural Basis for Oxygen Activation at a Dinuclear Iron Site

D. T Logan, Xiao-Dong Su, A. Ảberg, K. Regnström, J. Hajdu, H. Eklund and P. Nordlund

Structure, 4, 1053-1064 (1996)

Crystal Structure of the Xanthine Oxidase-Related Aldehyde Oxido-Reductase from D. gigas M.J. Romão, M. Archer, I. Moura, J.J.G. Moura, I. LeGall, R. Engh, M. Schneider, P. Hof, and R. Huber

Science, 270, 1170-1176 (1995)

A Structure-based Catalytic Mechanism for the Xanthine Oxidase Family of Molybdenum Enzymes

R.Huber, P.Hof, R.O.Duarte, I.J.G.Moura, I.Moura, I. LeGall, R.Hille, M.Archer and M.J.Romão

Proc. Nat. Acad. Sc. USA, 93, 8864-8851 (1996)

Structure of a Hyperthermophilic Tungstopterin Enzyme, Al- dehyde Ferredoxin Oxido-reductase

M. K. Chan, S. Mukund, A. Kletzin, M. W. W. Adams, and D. C. Rees

Science, 267, 1463-1469 (1995)

Crystal Structure of DMSO Reductase: Redox-Linked Changes in Molybdopterin Coordination

H. Schindelin, C. Kisker, J. Hilton, K.V. Rojagopalan and D. C. Rees

Science, 272, 1615-1621 (1996)

Characterization of Crystalline Formate Dehydrogenase $\mathrm{H}$ from Escherichia coli

V.N.Gladyshev, I.C. Boyington, S.V.Khangulov, D.A.Gtaham, T.C. Stadtman and P.D.Sun

J.Biol.Chem., 27, 8095-8100 (1996)

Crystal Structure of a Purple Acid Phosphatase Containing a Dinuclear Fe(II)-Zn(II) Active Site

N. Stäter, T. Klabunde, P. Tucker, H. Witzel, and B. Krebs Science, 268, 1489-1492 (1995)

Crystal Structure of Desulforedoxin from Desulfovibrio gigas Determined at $1.8 \AA$ Resolution: A Novel Nom-Heme Iron Protein Structure

M. Archer, R. Huber, P. Tavares, I. Moura, I.J.G. Moura, M.A. Carrondo, L. C. Sieker, I. LeGall and M. I. Romão I. Mol. Biol., 251, 690-703 (1995)

\section{HITACHI}

\section{ESPECTROFOTÓMETROS DE UVIVIS, DUPLO FEIXE CONTROLADO POR PC COM CARTA GLPIGMP MODELO U-2010} da nossa Representada "HITACHI"

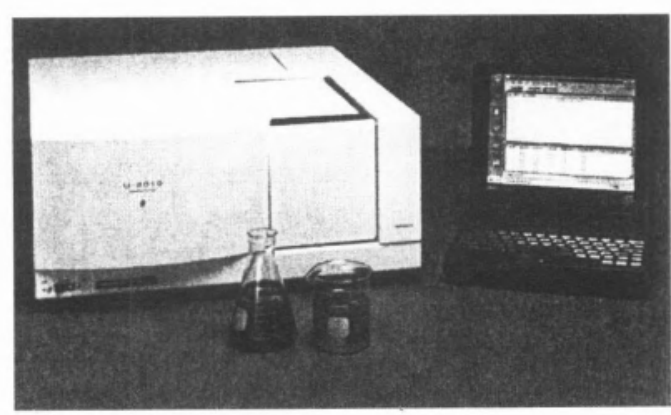

- O software oferece:

- metodos

- scanning

- "ratio" DNA e RNA

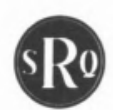

SOQUÍMICA
Sociedade de Representações e Química, Lda.

Rua Coronel Santos Pedroso, 15 • 1500 LISBOA • Tel.: 7165160 • Fax: 7165169 Sede Social: Av. da Liberdade, 220-2 $2^{\circ} 129$ LISBOA CODEX

Rua 5 de Outubro, $269 \bullet 4100$ PORTO • Tels.: 6093069 • Fax: 6000834 